\begin{tabular}{|c|c|c|}
\hline ISo Fin & $\begin{array}{c}\text { Bulletin of Pharmaceutical Sciences } \\
\text { Assiut University }\end{array}$ & \\
\hline 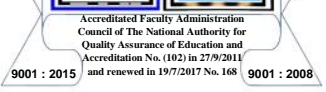 & $\begin{array}{l}\text { Website: http://bpsa.journals.ekb.eg/ } \\
\text { e-mail: bullpharm@aun.edu.eg }\end{array}$ & $\begin{array}{l}\text { BULL. PHARM. SCI. } \\
\text { Assiut Univ. }\end{array}$ \\
\hline
\end{tabular}

\title{
DIFFERENTIAL CYTOKINE PROFILES IN PATIENTS WITH VIRAL AND NON-VIRAL RELATED LIVER CIRRHOSIS
}

Sara A El-Mokhtar ${ }^{1}$, Omnia El-Badawy ${ }^{2}$, Helal F Hetta ${ }^{2}$, Mohamed O Abdel-Malek ${ }^{3}$ and Noha A Afifi ${ }^{2}$

${ }^{1}$ Department of Microbiology and Immunology, Faculty of Pharmacy, Assiut University, Assiut, Egypt

${ }^{2}$ Department of Medical Microbiology and Immunology, Faculty of Medicine, Assiut University, Assiut, Egypt

${ }^{3}$ Department of Tropical medicine and Gastroenterology, Faculty of Medicine, Assiut University, Assiut, Egypt

Cytokines are pleiotropic peptides that are produced by nearly every nucleated cell in the human body. The liver is one of the most affected tissues. Hepatic inflammation, apoptosis and necrosis of liver cells, cholestasis, fibrosis, and cirrhosis are all mediated by cytokines. Interleukins (IL) like IL17 and IL10, the tumour necrosis factor (TNF) family of cytokines like $T N F-\alpha$, chemokines like $I L-8$, and others are representing these cytokines. There is growing evidence that numerous cytokines play a key role in various aspects of liver disorders caused by viruses such as hepatitis $C$ and $B$ viruses, as well as non-viral liver diseases like autoimmune liver disease, Budd-Chiari syndrome, and other non-viral liver diseases. Biological response of cytokines involved in inflammation and cirrhosis may have an impact on the prognosis of certain disorders With respect to acute and chronic liver diseases. The present state of cytokine thoughts and functions in the pathogenesis of liver diseases, with a focus on liver cirrhosis, is discussed in this review.

\section{INTRODUCTION}

\section{Cytokines and their role in liver damage Definition}

Cytokines are proteins or peptides that are produced by cells, primarily immune cells, as a result of a stimulus. The main functions of cytokines are to regulate immunological responses and to influence the behavior of various cell types by modulating proliferation, differentiation, and activation ${ }^{1}$. Cytokines are engaged in nearly every function of inflammation and immunological responses, from the stimulation of the innate immune response to the production of cytotoxic $\mathrm{T}$ cells and the manufacture of antibodies by the humoral immune system ${ }^{2}$. They also work with the rest of the body to coordinate immune system operations. There are many classes of cytokines as interleukins (ILs), interferons (IFNs), transforming growth factors (TGFs), tumor necrosis factors (TNFs) and colonystimulating factors $(\mathrm{CSFs})^{3}$.

\section{Role of cytokines in immune response} activation and immunomodulation

Cytokines are best known for their roles in inflammation, immunological response, tissue repair, and organ failure ${ }^{4}$. The needed immune response is formed by the modulation and balance of T-helper 1 (Th1) and T-helper 2 (Th2) cell types. Th1 and Th2 cells modulate various immune response pathways, which is adapted to human immunity. Th-1-driven cellular immunity is the initial line of defense against viruses and other intracellular pathogens, as well as the elimination of malignant cells. Th2 cells are responsible for the type-2 humoral immune system, allergy responses, and up-regulation of antibody production in the fight against external pathogens, such as parasite eradication ${ }^{5}$. 
Overactivation of any pathway can result in disease, and each pathway can suppress the other $^{6}$.

Th1 cells secrete a wide range of cytokines, including IL-2, IFN- $\alpha$ and IL-12, Th2 cells, on the other hand, produce IL-5 and IL-4. Other cell types release equivalent levels of IL-10. Previously, it was considered that IL10 was the primary mechanism by which Th1 cells is down-regulated by $\mathrm{Th}^{2}$ cells $^{7}$. Th1 cytokines behave as pro-inflammatory mediators which affect the pathophysiology of numerous disorders, particularly liver damage. IL-12 and IFN- $\gamma$, for example, are well-known pro-inflammatory Th1 cytokines. They, together with TNF- $\alpha$, IL- 6 , and IL-1 $\beta$, play an important role in the human defense against bacterial infections in the liver ${ }^{8}$. Furthermore, a large number of cytokines have antiinflammatory effects, including IL-1 receptor antagonist (IL-1Ra), IL-22, transforming growth factor- $\beta$ (TGF- $\beta$ ) and the most important anti-inflammatory cytokine IL- $10^{9}$. When confronted with an infectious agent, the balance of anti-inflammatory/pro-inflammatory cytokines is disrupted. Anti-inflammatory cytokines are down-regulated as a result of proinflammatory cytokines being over-regulated. This occurrence indicates the severity for disease $^{10}$. As a result, the immune system regulatory process aims to restore cytokine balance to normal homeostatic levels with no increase or decrease of any of them. Although Th1/Th2 regulation is extremely complicated, its value in the research of various illnesses and autoimmune disorders cannot be overstated. Trying to define all of the mechanisms that control these processes, as well as the use of immunomodulatory compounds, will aid the development of therapies to control Th1/Th2 balance during diseases ${ }^{11}$.

Helper $\mathrm{T}$ cells have four types of cells which are :Th1, Th17,Th2, and Treg cells based on their biological properties ${ }^{12}$.

Tregs are a type of $\mathrm{T}$ cell that make up roughly $5-10 \%$ of $\mathrm{CD} 4+\mathrm{T}$ cells in the peripheral circulation ${ }^{13}$. Treg cells mainly express FOXP3, CD4, and CD25. FOXP3 is the transcription factor that is specific to Treg cells. As a result, Treg cells are frequently described as $\mathrm{CD} 4+\mathrm{CD} 25+\mathrm{FOXP} 3+$ cells. $^{14}$. Treg cells function in the regulation of immunological tolerance in the body to maintain normal immune responses in a normal physiological condition $^{15}$. In a study of hepatic fibrosis caused by the hepatitis $\mathrm{C}$ virus, Claassen et al. observed a substantial number of Treg cells in the liver, and a higher number of Treg cells was connected to less severe liver fibrosis, suggesting that Treg cells may act as a fibrosis inhibitor ${ }^{16}$. These cells not only contributed to the cause of liver cirrhosis, but also worked as a positive regulator, avoiding liver fibrosis as the disease advanced. Treg cells' anti-hepatic fibrosis function is most likely linked to IL-10 production $^{17}$. Treg cells release IL-10, a key immunosuppressive agent. It protects liver cells and fights hepatic fibrosis and hepatocellular damage $^{18}$. The anti-liver fibrosis effect of IL-10 may be mediated by one or more of the mechanisms listed below: (1) L-10 inhibits HSC activation by inhibiting or downregulating TNF, PDGF, and COX-2 synthesis in liver tissues; and (2) TGF1 stimulates HSCs to make collagen fibers, while IL-10 inhibits TGF1I expression, preventing fibrosis. (3) IL10 reduces the proliferative response in acute liver damage, reducing the development and progression of liver fibrosis ${ }^{19}$.

In contrast to Tregs, Th17 cells have important role in inflammatory responses, autoimmune disorders, malignancies, and infectious diseases. By mobilizing, attracting, and activating neutrophils, IL-17 increases inflammation and the advancement of autoimmune diseases ${ }^{20}$. According to Sun et al., an increase in Th17 cells in the liver of individuals with hepatitis B-associated liver cirrhosis supported an increase in HSC activity, which finally led to cirrhosis deterioration ${ }^{21}$. According to a study by Sparna et al., the more severe the liver fibrosis is, the more Th17 cells are detected, suggesting that Th17 cells may have a role in the progression of liver fibrosis ${ }^{22}$.

Treg and Th17 are related to progression of liver cirrhosis, and they collaborate on differentiation and development, but they are constrained by one another. The discovery of a relationship between Treg and Th17 cells and liver cirrhosis will aid researchers in better understanding how liver diseases arise ${ }^{12}$.

\section{Cytokines' role in liver damage}

Cytokines have been linked to the development and progression of chronic liver disease. The liver is essential for cytokine metabolism. All cells in the liver can create cytokines, which stimulate neighboring cells (paracrine effect) or stimulate themselves (autocrine effect), resulting in increased 
cytokine production and an inflammatory response $^{23}$. Whereas certain cytokines release from the resting cells of the liver, the levels and types of cytokines produced by stimulation by a range of inducers, such as LPS, viruses, chemical agents, malignancies, hepatic ischeemia and alcohol intake, are raised substantially after stimulation ${ }^{24}$.

Several cytokines appear to be engaged in developing liver diseases, according to emerging research ${ }^{25}$. Data suggests that, in liver fibrosis transforming growth factor (TGF- $\beta$ ) plays a major role. IL- $1 \beta, 6,8$, TNF- $\alpha$, and IFN- $\gamma$, on the other hand, appear to have a role in hepatic inflammatory responses. Neither IFN- nor IL-10 can reverse fibrotic/inflammatory processes, according to the findings. Furthermore, Although the relationship between persistent hepatocellular damage, hepatic inflammation, and cirrhosis has yet to be fully elucidated in chronic liver disease, cytokines may represent the common thread connecting these disparate clinical outcomes $^{26}$.

\section{Liver cirrhosis \\ Definition}

Cirrhosis is a widespread process characterized by fibrosis and the production of nodules. Cirrhosis is the end result of the fibrogenesis ${ }^{27}$. Cirrhosis is modification of the liver morphology characterized by the full destruction of its normal structure as a result of the production of nodular patches of hepatic parenchyma surrounded and separated by fibrous septa, both of which implicate the entire $\operatorname{organ}^{28}$.

Cirrhosis is an irreversible transformation because the changed hepatic architecture does not reverse following complete and protracted cessation of the damaging agent/s' action. Altered functions may remain compensated for variable lengths of time. Still, in due course, they decompensate, and end-stage complications occur, which become fatal. The worst of these complications is the development of hepatocellular carcinoma (HCC), one of the most fatal cancers in humans ${ }^{29}$.

\section{Cirrhosis etiologic types and other end-stage CLD}

Cirrhosis mostly caused by environmental agents and causes. Cirrhosis was previously thought to be the result of a protein deficit in chronic alcoholics and the impoverished population of poor countries until the mid1960s. Alcohol is directly hepatotoxic, and protein-calorie malnutrition does not produce cirrhosis, it was discovered soon after. The identification of the hepatitis B virus (HBV) was a huge step forward in the fight against cirrhosis, and chronic HBV infection caused the majority of CLD and HCC in underdeveloped nations and a smaller proportion in industrialized western countries by the mid-1970s ${ }^{30}$. The extensive use of blood transfusions, combined with increased intravenous drug addiction, led to a rapid rise in HCV-related CLD and HCC in the post-World War II period. HBV-related diseases have declined after control methods for this virus infection, such as vaccination, by the early twenty-first century. HCV-related CLD reduced in industrialized countries while rising in other parts of the world, while HBV-related CLD decreased just slightly ${ }^{28}$.

Alcoholic, non-alcoholic steatohepatitis (NASH), and viral cirrhosis, particularly hepatitis $\mathrm{C}$, are all becoming more common in Western countries. Hepatitis viruses B and C are the most common causes in underdeveloped countries. CLD has always had a minor number of intrahepatic biliary tract disorders and autoimmune liver disease. Cryptogenic Cirrhosis is a condition for which the cause is unknown. It is a diagnosis of exclusion ${ }^{28}$. There is a wide number of CLD caused by nonalcoholic fatty liver disease (NAFLD), most of which clinically present as cryptogenic ${ }^{28 \& 31 \& 32}$.

\section{Hepatitis B virus-related cirrhosis Identification of $\mathrm{HBV}$ as etiology}

The presence of markers of HBV in blood and virus components in the liver tissue are used to make the diagnosis of HBV-related chronic liver disease. The presence of IgG class antibody indicates a previous infection, whereas a current infection is proven by detection of HBsAg. Current infection also proven by detection of HBeAg and HBV DNA as they indicate the presence of active replication of the virus, and the titer of HBV DNA is indicative of the degree of viral replication. In the liver, $\mathrm{HBV}$ is randomly distributed in hepatocytes ${ }^{33}$. Therefore, the absence of $\mathrm{HBV}$ viral components in liver biopsy does not exclude the presence of the virus in the hepatocytes, as they are or were seen in about 1/50,000 part of the organ ${ }^{32}$. 


\section{Prevalence and temporal changes}

In the mid-1970s, the serological tests for diagnosing HBV infection became accessible and widely used, the prevalence of $\mathrm{HBV}$ related cirrhosis began to be recognized. It was quickly discovered that this viral infection is widespread over the world ${ }^{34}$. These infection rates are mirrored by the prevalence of HBVrelated cirrhosis. HBV is transmitted through the hematogenous pathway. Adults who are not immunized can develop acute icteric or nonicteric hepatitis, and most of the patients recover spontaneously and generate an immune response. Only 2-5 percent of infected adults develop chronic hepatitis, which can lead to cirrhosis ${ }^{35}$.

From the beginning of 1950 s till mid1990s, the usage of blood transfusions and intravenous drug misuse was widespread and led to increase in HBV infection and liver diseases. At the end of the twentieth century, 2 billion individuals were infected with $\mathrm{HBV}$, 350 million of them were HBV carriers, and 0.5 to 1.2 million people died each year from HBV-related chronic hepatitis, cirrhosis, and HCC. Hepatocellular carcinoma caused by HBV caused about 350,000 deaths per year ${ }^{36}$.

Strategies to control and prevent HBV were very important as obligatory vaccination of infants, this will reduce the danger and spread of HBV related cirrhosis and HCC. Liver fibrosis that is prior to liver cirrhosis can be reversed by treatment of HBV. Antiviral drugs and combination therapies are now used to control the HBV infection. Using these drugs in addition to control measures will help in reduction the prevalence of $\mathrm{HBV}$ related cirrhosis and $\mathrm{HCC}^{37}$.

\section{Hepatitis $\mathbf{C}$ virus related cirrhosis Evolution of knowledge}

$\mathrm{HCV}$, an RNA virus, can lead to chronic hepatitis, cirrhosis, and HCC. HCV and HBV have several differences in their biological interactions with the host. HCV enters the human body entirely by the hematogenous pathway, primarily through blood transfusions, to a lesser extent through intravenous drug misuse, and very rarely through maternalperinatal transmission (unlike $\mathrm{HBV}$ ). $\mathrm{HCV}$ infection typically starts much later in life than HBV infection. The beginning of injury of liver by $\mathrm{HCV}$ is mainly so mild that mostly shows no symptoms. about 85 percent of individuals suffering from $\mathrm{HCV}$ infection develop chronic inflammation, which will proceed to cirrhosis and HCC if not properly treated ${ }^{38,39}$.

\section{Identification of HCV as etiology}

The confirmation of the role of $\mathrm{HCV}$ in CLD is based on detection of the virus infection markers on specific immunological tests in the absence of evidence for other causes. These include anti-HCV antibody and HCV RNA, the anti-HCV antibody is specific as it represents active virus replication. Also, as in the case of HBV DNA, the quantitative assay of HCV RNA units would indicate the degree of virus replication. blood transfusion or intravenous drug misuse is the most common route of $\mathrm{HCV}$ transmission, so previous history is additional important proof $^{40}$.

In cirrhosis and chronic hepatitis, lymphoid cell aggregates scattered randomly in the fibrous septa are found in the liver in about $85 \%$ of these patients. This morphologic characteristic was found in 85.6 percent of HCV seropositive cases versus 13.2 percent of HCV seronegative cases of patients with endstage CLD who underwent living donor liver transplantation. The other microscopic evidence is focal macro-vesicular fatty change of hepatocytes ${ }^{41}$.

\section{Non-alcoholic fatty liver disease related cirrhosis}

Patients suffering from chronic liver disease with morphologic alterations of alcoholic hepatitis were termed NASH in the early $1980 \mathrm{~s}^{42,43}$. Pathologic changes in hepatic biopsy were found and the defect ranged from steatosis through steatohepatitis to fibrosis ${ }^{32,44,}$ ${ }^{45}$. The preferred name for the disease became NAFLD with NASH being the only one of the more important stages in its progression. Increased prevalence of NAFLD is mainly due to lifestyle changes causing diabetes prevalence and obesity.

\section{Autoimmune diseases and cirrhosis}

Autoimmune hepatitis is a chronic inflammatory disease that attacks the hepatocytes directly in contrast to the two cholestatic AILDs. Autoimmune hepatitis can appear at any age, mainly in females, although the two peak ages of occurrence are during childhood or adolescence and around the age of $40^{47}$. Elevated aminotransferase levels, autoantibody positivity, and increased $\mathrm{IgG}$ are all biochemical and serological features of 
autoimmune hepatitis. Autoantibody positivity is a key clinical characteristic of autoimmune hepatitis, allowing for quicker identification and differentiation between two kinds of the illness. Patients with autoimmune hepatitis type-1 have ANA and/or anti-smooth muscle autoantibodies (SMA), but those with AIH type-2 have anti-liver kidney type-1 autoantibody (anti-LKM-1) or anti-liver cytosol type-1 (anti-LC-1) ${ }^{48,49}$. Although the etiology of autoimmune hepatitis is unknown, available research clearly suggests that hereditary and environmental factors interact. The discovery that the hepatitis $\mathrm{C}$ virus shares a significant degree of sequence homology with cytochrome P450-2D6, the auto-antigenic target of antiLKM-1 autoantibodies, has led to the theory that molecular mimicry could cause autoimmune hepatitis in genetically susceptible individuals $^{50}$. Hepatitis B virus, cytomegalovirus, and herpes simplex virus are all potential triggers for autoimmune hepatitis $^{51}$.

\section{Budd-Chiari syndrome and cirrhosis}

The Budd-Chiari syndrome is a condition that affects humans. According to EASL standards, Budd-Chiari syndrome (BCS) is defined as obstruction of the hepatic venous outflow system in the absence of right-sided heart failure or constrictive pericarditis. Lesions in the large or small hepatic veins (HV) or the suprahepatic section of the inferior vena cava can cause BCS (IVC) ${ }^{52}$

Acute, subacute, chronic, and fulminant Budd-Chiari syndrome are the four clinical variations. Abdominal pain, ascites, and hepatomegaly describe the acute type, which lacks indications of portal hypertension. Fulminant hepatitis can complicate this kind. Regardless of the cause, the chronic form is difficult to distinguish from cirrhosis. The symptoms of acute BCS with portal hypertension describe the subacute variant. It is the outcome of a prior thrombosis $\operatorname{progression}^{53}$.

The extent and rapidity of hepatic-vein blockage, as well as whether a venous collateral circulation has established to decompress the liver sinusoids, determine the clinical appearance of the Budd-Chiari syndrome ${ }^{54}$. Thrombosis of all main hepatic veins is common in acute Budd-Chiari syndrome, while only one-third of patients have it in sub-acute
Budd-Chiari syndrome. The chronic type is manifested as cirrhosis problems ${ }^{55}$.

\section{Cryptogenic cirrhosis}

Cirrhosis or end-stage CLD are diagnosed in cryptogenic cases where no known cause or causes can be established, meaning that the cause is unknown at the time. As awareness of the different causes of chronic liver illnesses and the probability of cirrhosis progression has increased, this part of "cryptogenic cirrhosis" has diminished over time. The proportion of this group in developed countries has decreased from over $20 \%$ in the mid-1990s to around 5\% in recent years ${ }^{56}$. Currently, it is recognized that certain cases of NAFLD proceed to cirrhosis, and some cases formerly categorized as "cryptogenic" have been diagnosed as NAFLD $^{32 \& 56 .}$.

\section{Immunological dysfunction in cirrhosis Innate immune dysfunction}

IL-1, IL-3, IL-6, TNF-, transforming growth factor (TGF-), IFN-, and other cytokines are cleared mostly through the liver. Cirrhosis, on the other hand, causes the liver to be unable to remove cytokines, resulting in continuous activation of neutrophils in the peripheral circulation $^{57}$ and subsequently impair the neutrophils functions like migration and phagocytosis ${ }^{58}$. In addition, higher endotoxin absorption and bacterial translocation result in a long-term rise in cytokines. Removing endotoxins in vitro ${ }^{59}$ and reducing endotoxemia in vivo with probiotics ${ }^{60}$ enhances the function of polymorphonuclear leukocytes in cirrhosis.

Cirrhosis impairs innate immunity by lowering the bactericidal potential of the organism by compromising the development and function of pattern recognition receptors (PRRs) and other proteins ${ }^{61}$. PRRs recognize a variety of pathogen-related molecular patterns (PAMPs). TLRs (Toll-Like Receptors) are the most well-studied PRRs, and they play an important role in cirrhosis-related immunological dysfunction (CAID $)^{62-64}$. The acquired modification of TLRs and associated signaling pathways is a significant cause of innate immune failure in cirrhosis ${ }^{65}$.

Reduced monocyte HLA-DR expression, often known as immune paralysis, is a wellknown feature of acute liver failure and septic shock. It was also recently detected in people with liver cirrhosis. Anti-inflammatory 
cytokines like IL-6 and IL-10 are up, while proinflammatory cytokines like IL-1 and TNF- are down, causing immunological paralysis ${ }^{66}$.

Immunomodulatory agents such as the granulocyte-macrophage colony-stimulating factor (GM-CSF) and interferon-gamma (IFN$\gamma$ ) can improve monocyte functions and should be investigated further ${ }^{67}$. Endotoxemia, through an IL-10-mediated mechanism, may lead to HLA-DR downregulation in cirrhotic patients. Low levels of proinflammatory cytokines including TNF and nitric oxide synthase, as well as allostimulatory activity, were found in monocytes with low HLA-DR expression ${ }^{68}$.

Classical CD14+CD16 monocytes and non-classical CD14+CD16+ monocytes are the two types of monocytes. In individuals with chronic liver disease, there is a considerable increase in the non-classical subsets, which is linked to collagen-producing hepatic stellate cell activation, pro-inflammatory cytokine production, and clinical progression ${ }^{69}$. A low lymphocyte-to-monocyte ratio has been postulated as an independent prognostic marker in liver cirrhosis ${ }^{70}$. (sCD163) is the soluble form of CD163 marker which is responsible for macrophage activation and it is released in the circulation $^{71}$. It rises with the Child-Pugh score in cirrhosis and has a strong relationship with the hepatic venous pressure gradient, and hence with portal hypertension ${ }^{72}$. Waismann et al. ${ }^{73}$ showed that sCD163 had an independent risk factor for death and variceal bleeding in cirrhotic patients, highlighting the possibility of its future development as a new pharmaceutical target. Cirrhotic patients' peritoneal macrophages have been found to produce nitric oxide and angiogenic peptides, which have been linked to SBP in the study ${ }^{74}$.

Finally, Tonan et al. $^{75}$ reported that Kupffer cell failure contributes to the etiology of non-alcoholic steatohepatitis, since CD14positive Kupffer cells increase along with necroinflammation grade and fibrosis stage. Cirrhotics also have problems with neutrophils, which are the first line of defense against bacterial infection. On the one hand, this impairs neutrophil delivery to the infective center, while on the other hand, it results in lower neutrophil phagocytic activity as compared to those in the healthy population ${ }^{67}$.

\section{Adaptive immune dysfunction}

Cirrhotic individuals frequently experience adaptive immune dysfunction. It has long been known that alcoholic liver disease produces several abnormalities in $\mathrm{B}$ and $\mathrm{T}$ cell activity. In patients with alcoholic liver illness, Nourieta et al. discovered a widespread deficiency of $\mathrm{T}$ cells and hyperactivity of $\mathrm{B}$ cells. These individuals have circulating $\operatorname{IgG}$ and $\mathrm{T}$ lymphocytes that identify epitopes against antigens formed from lipid peroxidation, as well as an increase in hepatic synthesis of proinflammatory cytokines and chemokines ${ }^{76}$. Doi et al. found that memory CD27+ B cells were reduced in the peripheral blood of cirrhotic patients, regardless of the cause, and that this reduction resulted in poor TNF- and IgG production, vaccination hyporesponsiveness, and susceptibility to bacterial infection ${ }^{77}$.

Because Th1 lymphocytes express antifibrotic cytokines and Th2 lymphocytes express profibrotic cytokines, the Th1/Th2 lymphocyte ratio is critical. Cirrhosis causes an increase in CD8+ cells, which lowers the CD4+/CD8+ cell ratio and favors the fibrogenic process $^{78}$. A study performed by Marquez et al. ${ }^{79}$ showed that in patients with liver cirrhosis, the immune system's monocytes and $\mathrm{T}$ cells are severely disrupted. Importantly, in cirrhosis, $\mathrm{T}$ cells are activated for a longer period of time as a result of the prolonged antigenic input. Apoptosis markers and activation-induced cell death (AICD) are increased in activated CD4+ and CD8+ cells, apparently to maintain lymphocyte homeostasis. Cirrhotic patients have higher levels of the apoptotic marker CD95+ in their memory cell population than healthy controls. These $\mathrm{T}$ cells are unable to proliferate after receiving a new antigenic load, resulting in immunological suppression due to the exhaustion of the adaptive immune response ${ }^{80}$.

\section{Cytokines and treatment of inflammatory liver diseases}

Most acute and chronic liver illnesses are characterized by inflammatory processes characterized by elevated expression of many pro- and anti-inflammatory cytokines in the liver. These cytokines are responsible for a variety of inflammatory liver diseases, including fibrosis and cirrhosis. Many cytokines are thought to play a role in various aspects of inflammatory liver disease and liver tissue repair, according to accumulating evidence.(Table 1$)^{81}$. 
Table 1: Summary of cytokines involved in inflammatory liver disease ${ }^{81}$

\begin{tabular}{|c|c|c|}
\hline Group of cytokine & Example of cytokine & Effect \\
\hline \multirow{4}{*}{$\begin{array}{l}\text { Proinflammatory } \\
\text { cytokines }\end{array}$} & $\begin{array}{l}\text { Cytokines of the interleukin-1 (IL-1) } \\
\text { type (IL-1 } \alpha, \text { IL- } 1 \beta \text {, TNF- } \alpha \text { ) }\end{array}$ & $\begin{array}{l}\text { They're pro-inflammatory cytokines that help with } \\
\text { protein synthesis in the acute phase. }\end{array}$ \\
\hline & Interferon-g (IFN- $\gamma)$ & $\begin{array}{l}\text { immunoregulatory T-helper cell (Th) } 1 \text { cytokine, } \\
\text { induces TNF } \alpha\end{array}$ \\
\hline & Interleukin-12 & Th-1-directing cytokine \\
\hline & Interleukin-18 & $\begin{array}{l}\text { IFN-g-inducing factor, proinflammatory at a very } \\
\text { early step in the immune response }\end{array}$ \\
\hline \multirow{8}{*}{$\begin{array}{l}\text { Anti- } \\
\text { inflammatory } \\
\text { cytokines }\end{array}$} & IL-1 Receptor antagonist & $\begin{array}{l}\text { member of the IL-1 family; blocks binding of IL-1 } \\
\text { to cell-surface receptors, prototype anti- } \\
\text { inflammatory cytokine }\end{array}$ \\
\hline & Soluble IL-1 receptor type II & binds circulating IL-1 \\
\hline & $\begin{array}{l}\text { Soluble tumor necrosis factor } \\
\text { receptor (TNFR) p55 (I)/p75 (II) }\end{array}$ & $\begin{array}{l}\text { naturally occurring TNF inhibitors, comprised of } \\
\text { extracellular domains of the two known TNFRs, } \\
\text { p55 and p75, block TNF-regulated inflammatory } \\
\text { processes }\end{array}$ \\
\hline & IL-18 binding protein & neutralizes IL-18 \\
\hline & $\begin{array}{l}\text { Gp130-signaling cytokines (IL-6, IL- } \\
11 \text {, leukemia inhibitory factor, } \\
\text { oncostatin M, ciliary neurotrophic } \\
\text { factor, cardiotrophin) }\end{array}$ & $\begin{array}{l}\text { pro- and anti-inflammatory activities, stimulation } \\
\text { of most acute phase proteins. IL- } 6 \text { regulates hepatic } \\
\text { regeneration and immunoglobulin synthesis }\end{array}$ \\
\hline & Interleukin-10 & $\begin{array}{l}\text { prototype anti-inflammatory cytokine, regulates B- } \\
\text { cell function }\end{array}$ \\
\hline & IL-4, IL-13 & $\begin{array}{l}\text { Th- } 2 \text { cytokines, regulate B-cell function, suppress } \\
\text { synthesis of proinflammatory cytokines }\end{array}$ \\
\hline & Adiponectin & $\begin{array}{l}\text { adipokine }- \text { induces anti-inflammatory cytokines } \\
\text { (IL-10, IL-1RA) and suppresses endotoxin induced } \\
\text { TNFa expression }\end{array}$ \\
\hline \multirow{3}{*}{$\begin{array}{l}\text { Cytokines } \\
\text { involved } \\
\text { immune } \\
\text { responses }\end{array}$} & IL2, IL-4, IL-7, IL-9, IL-12, IL15 & \\
\hline & Th-1 cytokines (IL-2, IFN- $\gamma$ ) & direct anti-viral response, proinflammatory \\
\hline & Th2-cytokines (IL-4, IL-5, IL-10) & $\begin{array}{l}\text { mediate inflammation, allergic responses and } \\
\text { immunoglobulin synthesis }\end{array}$ \\
\hline \multirow{3}{*}{$\begin{array}{l}\text { Cytokines } \\
\text { involved in acute } \\
\text { liver failure }\end{array}$} & TNF and TNFR p55/p75 & \\
\hline & Death receptors (Fas, Fas ligand) & critically involved in liver injury and apoptosis \\
\hline & IL-18 & $\begin{array}{l}\text { mediates TNF-and Fas-related experimental liver } \\
\text { failure }\end{array}$ \\
\hline $\begin{array}{l}\text { Fibrogenic } \\
\text { cytokines }\end{array}$ & Transforming growth factor-b & $\begin{array}{l}\text { Prototype fibrogenic cytokine, upregulation by } \\
\text { proinflammatory cytokines ,Platelet derived growth } \\
\text { factor (PDGF) and Fibroblast growth factor (FGF) }\end{array}$ \\
\hline \multirow{2}{*}{$\begin{array}{l}\text { Antifibrogenic } \\
\text { cytokines }\end{array}$} & Hepatocyte growth factor (HGF) & $\begin{array}{l}\text { anti-fibrogenic , anti-apoptotic and promotes liver } \\
\text { regeneration }\end{array}$ \\
\hline & Interferon-a (IFN- $\alpha)$ & $\begin{array}{l}\text { anti-viral, immunomodulatory, anti-inflammatory, } \\
\text { anti-fibrogenic }\end{array}$ \\
\hline
\end{tabular}

\section{REFERENCES}

1. G. A. G. Morán, R. Parra-Medina, A. G. Cardona, P. Quintero-Ronderos, and É. G. Rodríguez, "Cytokines, chemokines and growth factors, in Autoimmunity: From Bench to Bedside [Internet]", El Rosario University Press (2013).

2. A. K. Abbas, A. H. Lichtman, and S. Pillai, "Cellular and molecular immunology E-book: Elsevier Health Sciences (2014).
3. S. Kany, J. T. Vollrath, and B. Relja, "Cytokines in inflammatory disease",Int J Mol Sci, 20(23), 6008 (2019).

4. P. Berraondo, M. F. Sanmamed, M. C. Ochoa, I. Etxeberria, M. A. Aznar, J. L. Pérez-Gracia, M. E. Rodríguez-Ruiz, M. Ponz-Sarvise, E. Castañón, and I. Melero, "Cytokines in clinical cancer immunotherapy", Br J Cancer, 120(1), 615 (2019).

5. M. Ruterbusch, K. B. Pruner, L. Shehata, and M. Pepper," In vivo CD4+ T cell differentiation and function: revisiting the 
Th1/Th2 paradigm", Annu Rev Immunol, 38, 705-725 (2020).

6. S. Romagnani, "T-cell subsets (Th1 versus Th2)", Ann Allergy Asthma Immunol, 85(1), 9-21 (2000).

7. G. R. Gandhi, M. T. S. L. Neta, R. G. Sathiyabama, J. d. S. S. Quintans, A. M. d. O. e Silva, A. A. de Souza Araújo, N. Narain, L. J. Q. Júnior, and R. Q. Gurgel, "Flavonoids as Th1/Th2 cytokines immunomodulators: A systematic review of studies on animal models", Phytomedicine, 44, 74-84 (2018).

8. J. C. Ozougwu, "Physiology of the liver",Int J Pharm Biol Sci, 4(8), 13-24 (2017).

9. S. M. Gray and M. H. Bloch, "Systematic review of proinflammatory cytokines in obsessive-compulsive disorder", Curr Psychiatry Rep, 14(3), 220-228(2012).

10. J. M. Cicchese, S. Evans, C. Hult, L. R. Joslyn, T. Wessler, J. A. Millar, S. Marino, N. A. Cilfone, J. T. Mattila, J. J. Linderman, and D. E. Kirschner, "Dynamic balance of pro- and antiinflammatory signals controls disease and limits pathology", Immunol Rev, 285(1), 147-167 (2018).

11. J. D. Farrar, H. Asnagli, and K. M. Murphy, "T helper subset development: roles of instruction, selection, and transcription", J Clin Invest, 109(4), 431435 (2002).

12. Y.-T. Lan, Z.-1. Wang, P. Tian, X.-N. Gong, Y.-C. Fan, and K. Wang, "Treg/Th17 imbalance and its clinical significance in patients with hepatitis Bassociated liver cirrhosis", Diagn Pathol, 14(1), 114 (2019).

13. X.-P. Nan, Y. Zhang, H.-T. Yu, R.-L. Sun, M.-J. Peng, Y. Li, W.-J. Su, J.-Q. Lian, J.P. Wang, and X.-F. Bai, "Inhibition of viral replication downregulates $\mathrm{CD} 4+$ CD25high regulatory $\mathrm{T}$ cells and programmed death-ligand 1 in chronic hepatitis B", Viral Immunol, 25(1),21-28 (2012).

14. A. M. Bilate and J. J. Lafaille, "Induced CD4+ Foxp3+ regulatory $\mathrm{T}$ cells in immune tolerance", Annu Rev Immunol, 30, 733-758 (2012).

15. I. Mannaerts, N. R. Nuytten, V. Rogiers, K. Vanderkerken, L. A. van Grunsven, and A. Geerts, "Chronic administration of valproic acid inhibits activation of mouse hepatic stellate cells in vitro and in vivo", Hepatology, 51(2), 603-614 (2010).

16. A. Tanaka and S. Sakaguchi, "Targeting Treg cells in cancer immunotherapy", Eur J Immunol, 49(8), 1140-1146 (2019).

17. Y.-T. Lan, Z.-1. Wang, P. Tian, X.-N. Gong, Y.-C. Fan, and K. Wang, "Treg/Th17 imbalance and its clinical significance in patients with hepatitis Bassociated liver cirrhosis", Diagn Pathol, 14(1), 1-9 (2019).

18. J. M. Rojas, M. Avia, V. Martín, and N. Sevilla, "IL-10: A Multifunctional Cytokine in Viral Infections", J Immunol Res, 6104054 (2017).

19. L.-J. Zhang, W.-D. Zheng, Y.-X. Chen, Y.-H. Huang, Z.-X. Chen, S.-J. Zhang, M.N. Shi, and X.-Z. Wang, "Antifibrotic effects of interleukin-10 on experimental hepatic fibrosis", Hepatogastroenterology, 54(79), 2092 (2007).

20. D. B. O'Quinn, M. T. Palmer, Y. K. Lee, and C. T. Weaver, "Emergence of the Th17 pathway and its role in host defense", Adv Immunol, 99, 115-163 (2008).

21. H. Sun, J. Zhang, H. Zhang, Z. Zou, F. Wang, and J. Jia, "Increased Th17 cells contribute to disease progression in patients with $\mathrm{HBV}$-associated liver cirrhosis", J Viral Hepat, 19(6), 396-403 (2012).

22. T. Sparna, J. Rétey, K. Schmich, U. Albrecht, K. Naumann, N. Gretz, H.-P. Fischer, J. G. Bode, and I. Merfort, "Genome-wide comparison between IL-17 and combined TNF-alpha/IL-17 induced genes in primary murine hepatocytes", BMC Genomics, 11(1),1-14 (2010).

23. L. Hammerich and F. Tacke, "Interleukins in chronic liver disease: lessons learned from experimental mouse models", Clin Exp Gastroenterol, 7, 297-306 (2014). 
24. L. Niederreiter and H. Tilg, "Cytokines and fatty liver diseases", Liver Res, 2(1), 14-20 (2018).

25. M. Wan, J. Han, L. Ding, F. Hu, and P. Gao, "Novel Immune Subsets and Related Cytokines: Emerging Players in the Progression of Liver Fibrosis", Front Med, 8 (2021).

26. J. A. Del Campo, P. Gallego, and L. Grande, "Role of inflammatory response in liver diseases: Therapeutic strategies". World J Hepatol, 10(1), p. 1 (2018).

27. K. T. Suk and D. J. Kim, "Staging of liver fibrosis or cirrhosis: The role of hepatic venous pressure gradient measurement", World J Hepatol, 7(3), 607-615 (2015).

28. N. Nayak and D. Jain, "End stage chronic liver disease-yesterday, today and tomorrow. Liver Cirrhosis Causes, Diagnosis and Treatment", New York, NY: Nova Science Publishers.,p. 59-82 (2011).

29. P. A. McCormick and R. Jalan, Hepatic cirrhosis. Sherlock's Diseases of the Liver and Biliary System., p. 107-126. (2018).

30. E. Gupta, M. Bajpai, and A. Choudhary, "Hepatitis C virus: Screening, diagnosis, and interpretation of laboratory assays", Asian J Transfus Sci, 8(1), 19-25 (2014).

31. S. Saigal, N. C. Nayak, D. Jain, V. Kumaran, R. Mohanka, N. Saraf, A. Rastogi, N. Mehta, S. Nundy, and A. Soin, "Non-cirrhotic portal fibrosis related end stage liver disease in adults: evaluation from a study on living donor liver transplant recipients". Hepatol Int, 5(4), 882-889 (2011).

32. N. C. Nayak, N. Vasdev, S. Saigal, and A. S. Soin, "End-stage nonalcoholic fatty liver disease: evaluation of pathomorphologic features and relationship to cryptogenic cirrhosis from study of explant livers in a living donor liver transplant program". Hum Pathol, 41(3), 425-430 (2010).

33. N. C. Nayak and R. Sachdeva, "Localization of hepatitis B surface antigen in conventional paraffin sections of the liver. Comparison of immunofluorescence, immunoperoxidase, and orcein staining methods with regard to their specificity and reliability as antigen marker", Am J Pathol, 81(3) 479-492 (1975).

34. J. H. MacLachlan and B. C. Cowie, "Hepatitis B virus epidemiology". Cold Spring Harb Perspect Med, 5(5): p. a021410-a021410 (2015).

35. N. Nayak, "Cirrhosis and end-stage chronic liver disease: The changing scenes on etiopathogenesis", Curr Med Res Pra , 4, 62-77 (2014).

36. D. Lavanchy, "Hepatitis B virus epidemiology, disease burden, treatment, and current and emerging prevention and control measures", J Viral Hepat, 11(2), 97-107 (2004).

37. J. Lin, J.-F. Wu, Q. Zhang, H.-W. Zhang, and G.-W. Cao, "Virus-related liver cirrhosis: molecular basis and therapeutic options", World J Gastroenterol, 20(21), 6457-6469 (2014).

38. S. L. Chen and T. R. Morgan, "The natural history of hepatitis C virus (HCV) infection", Int J Med Sci, 3(2) 47 (2006).

39. V. K. Rustgi, "The epidemiology of hepatitis C infection in the United States", J Gastroenterol, 42(7), 513-521 (2007).

40. A. Baiocchini, F. Del Nonno, C. Taibi, U. Visco-Comandini, G. D’Offizi, M. Piacentini, and L. Falasca, "Liver sinusoidal endothelial cells (LSECs) modifications in patients with chronic hepatitis C", Sci Rep, 9(1): p. 1-10 (2019).

41. N. C. Nayak and S. A. Sathar, "Immunohistochemical detection of hepatitis $\mathrm{C}$ virus antigen in paraffin embedded liver biopsies from patients with chronic liver disease", Acta Histochem., 101(4), 409-419 (1999).

42. P. Angulo, "Nonalcoholic fatty liver disease", N Engl J Med, 346(16), 12211231 (2002).

43. R. Vuppalanchi and N. Chalasani, "Nonalcoholic fatty liver disease and nonalcoholic steatohepatitis: Selected practical issues in their evaluation and management", Hepatology, 49(1), 306-317 (2009). 
44. E. M. Brunt, Pathology of nonalcoholic steatohepatitis. Hepatol. Res., 33(2): p. 6871 (2005).

45. S. Hübscher, "Histological assessment of non-alcoholic fatty liver disease", Histopathology., 49(5), 450-465 (2006).

46. A. Wree, L. Broderick, A. Canbay, H. M. Hoffman, and A. E. Feldstein, "From NAFLD to NASH to cirrhosis-new insights into disease mechanisms. Nat. Rev. Gastroenterol", Hepatol, 10(11), 627636 (2013).

47. M. P. Manns, A. J. Czaja, J. D. Gorham, E. L. Krawitt, G. Mieli-Vergani, D. Vergani, J. M. Vierling, and D. American "Association for the Study of Liver, Diagnosis and management of autoimmune hepatitis", Hepatology, 51(6): p. 2193-213 (2010).

48. D. Vergani, F. Alvarez, F. B. Bianchi, E. L. Cancado, I. R. Mackay, M. P. Manns, M. Nishioka,and E. Penner, "International Autoimmune Hepatitis, Liver autoimmune serology: a consensus statement from the committee for autoimmune serology of the International Autoimmune Hepatitis Group", J Hepatol, 41(4), 677-83 (2004).

49. G. Mieli-Vergani and D. Vergani, "Paediatric autoimmune liver disease", Arch Dis Child, 98(12),1012-1017 (2013).

50. N. Kerkar, K. Choudhuri, Y. Ma, A. Mahmoud, D. P. Bogdanos, L. Muratori, F. Bianchi, R. Williams, G. Mieli-Vergani, and D. Vergani, "Cytochrome P4502D6(193-212): a new immunodominant epitope and target of virus/self cross-reactivity in liver kidney microsomal autoantibody type 1-positive liver disease", J Immunol, 170(3), 14811489 (2003).

51. D. P. Bogdanos, K. Choudhuri, and D. Vergani, "Molecular mimicry and autoimmune liver disease: virtuous intentions, malign consequences", Liver, 21(4), 225-232 (2001).

52. European Association For The Study of The Live, EASL Clinical Practice Guidelines: Vascular diseases of the liver. J. Hepatol., 64(1) 179-202 (2016).
53. X. Qi, G. Han, X. Guo, V. De Stefano, K. $\mathrm{Xu}, \mathrm{Z}$. Lu, H. Xu, A. Mancuso, W. Zhang, and X. Han, "The aetiology of primary Budd-Chiari syndrome-differences between the West and China. Aliment", Pharmacol Ther, 44(11-12), 1152-1167 (2016).

54. V. Bansal, P. Gupta, S. Sinha, N. Dhaka, N. Kalra, R. Vijayvergiya, U. Dutta, and R. Kochhar, "Budd-Chiari syndrome: imaging review". Br J Radiol, 91(1092), 20180441 (2018).

55. D. C. Valla, "Budd-Chiari syndrome/ hepatic venous outflow tract obstruction", Hepatol Int, 12(1), 168-180 (2018).

56. G. Ayata, F. D. Gordon, W. D. Lewis, E. Pomfret, J. J. Pomposelli, R. L. Jenkins, and U. Khettry, "Cryptogenic cirrhosis: clinicopathologic findings at and after liver transplantation", Hum Pathol, 33(11), 1098-1104 (2002).

57. V. Stadlbauer, R. P. Mookerjee, G. A. K. Wright, N. A. Davies, G. Jürgens, S. Hallström, and R. Jalan, "Role of Toll-like receptors 2, 4, and 9 in mediating neutrophil dysfunction in alcoholic hepatitis". Am J Physiol Gastrointest Liver Physiol, 296(1), 15-22 (2009).

58. C. Fiuza, M. Salcedo, G. Clemente, and J. M. Tellado, "In Vivo Neutrophil Dysfunction in Cirrhotic Patients with Advanced Liver Disease", J Infect Dis, 182(2), 526-533 (2000).

59. R. P. Mookerjee, V. Stadlbauer, S. Lidder, G. A. Wright, S. J. Hodges, N. A. Davies, and R. Jalan, "Neutrophil dysfunction in alcoholic hepatitis superimposed on cirrhosis is reversible and predicts the outcome", Hepatology, 46(3), 831-840 (2007).

60. V. Stadlbauer, R. P. Mookerjee, S. Hodges, G. A. Wright, N. A. Davies, and R. Jalan, "Effect of probiotic treatment on deranged neutrophil function and cytokine responses in patients with compensated alcoholic cirrhosis", J Hepatol, 48(6), 945-951 (2008).

61. N. Sipeki, P. Antal-Szalmas, P. L. Lakatos, and M. Papp, "Immune 
dysfunction in cirrhosis", World $J$ Gastroenterol, 20(10), 2564-2577 (2014).

62. L. Yang and E. Seki, "Toll-like receptors in liver fibrosis: cellular crosstalk and mechanisms", Front Physiol, 3, 138 (2012).

63. R. Broering, M. Lu, and J. F. Schlaak, "Role of Toll-like receptors in liver health and disease", Clin Sci, 121(10), 415-426 (2011).

64. T. Aoyama, Y.-H. Paik, and E. Seki, "Toll-like receptor signaling and liver fibrosis. Gastroenterol", Res Pract, 2010 (2010).

65. L. Cheng, Z. Zhang, G. Li, F. Li, L. Wang, L. Zhang, S. M. Zurawski, G. Zurawski, Y. Levy, and L. Su, "Human innate responses and adjuvant activity of TLR ligands in vivo in mice reconstituted with a human immune system", Vaccine, 35(45), 6143-6153 (2017).

66. C. G. Antoniades, J. Wendon, and D. Vergani, "Paralysed monocytes in acute on chronic liver disease", J Hepatol, 42(2), 163-165 (2005).

67. B. Gao, W. I. Jeong, and Z. Tian, "Liver: an organ with predominant innate immunity", Hepatology, 47(2), 729-736 (2008).

68. C.-Y. Lin, I.-F. Tsai, Y.-P. Ho, C.-T. Huang, Y.-C. Lin, C.-J. Lin, S.-C. Tseng, W.-P. Lin, W.-T. Chen, and I.-S. Sheen, "Endotoxemia contributes to the immune paralysis in patients with cirrhosis", $\boldsymbol{J}$ Hepatol, 46(5), 816-826 (2007).

69. H. W. Zimmermann, S. Seidler, J. Nattermann, N. Gassler, C. Hellerbrand, A. Zernecke, J. J. Tischendorf, T. Luedde, R. Weiskirchen, and C. Trautwein, "Functional contribution of elevated circulating and hepatic non-classical CD14+ CD16+ monocytes to inflammation and human liver fibrosis", PLoS One, 5(6) (2010).

70. J. Zhang, G. Feng, Y. Zhao, J. Zhang, L. Feng, and J. Yang, "Association between lymphocyte-to-monocyte ratio (LMR) and the mortality of HBV-related liver cirrhosis: a retrospective cohort study", BMJ open, 5(8), e008033 (2015).

71. K. Skogstrand, A. H. Thysen, C. S. Jørgensen, E. M. Rasmussen, A. B. Andersen, T. Lillebaek, D. M. Hougaard, and G. Houen, "Antigen-induced cytokine and chemokine release test for tuberculosis infection using adsorption of stimulated whole blood on filter paper and multiplex analysis", Scand J Clin Lab Invest, 72(3), 204-211 (2012).

72. H. Grønbaek, T. Sandahl, C. Mortensen, H. Vilstrup, H. Møller, and S. Møller, "Soluble CD 163, a marker of Kupffer cell activation, is related to portal hypertension in patients with liver cirrhosis. Aliment", Pharmacol Ther, 36(2), 173-180 (2012).

73. O. Waidmann, F. Brunner, E. Herrmann, S. Zeuzem, A. Piiper, and B. Kronenberger, "Macrophage activation is a prognostic parameter for variceal bleeding and overall survival in patients with liver cirrhosis", J Hepatol, 58(5), 956-961 (2013).

74. E. Gäbele, M. Mühlbauer, H. Paulo, M. Johann, C. Meltzer, F. Leidl, N. Wodarz, R. Wiest, J. Schölmerich, and C. Hellerbrand, "Analysis of monocyte chemotactic protein-1 gene polymorphism in patients with spontaneous bacterial peritonitis. World journal of gastroenterology", WJG., 15(44), 5558. (2009).

75. T. Tonan, K. Fujimoto, A. Qayyum, Y. Morita, O. Nakashima, N. Ono, A. Kawahara, M. Kage, N. Hayabuchi, and T. Ueno, "CD14 expression and Kupffer cell dysfunction in non-alcoholic steatohepatitis: Superparamagnetic iron oxide-magnetic resonance image and pathologic correlation", J Gastroenterol Hepatol, 27(4), 789-796 (2012).

76. K. Nouri-Aria, G. Alexander, B. Portmann, J. Hegarty, A. Eddleston, and R. Williams, "T and B cell function in alcoholic liver disease", J Hepatol, 2(2), 195-207 (1986).

77. H. Doi, T. K. Iyer, E. Carpenter, H. Li, K. M. Chang, R. H. Vonderheide, and D. E. 
Kaplan, "Dysfunctional B-cell activation in cirrhosis resulting from hepatitis $\mathrm{C}$ infection associated with disappearance of CD27-Positive B-cell population", Hepatology, 55(3), 709-719 (2012).

78. H. L. Lee, J. W. Jang, S. W. Lee, S. H. Yoo, J. H. Kwon, S. W. Nam, S. H. Bae, J. Y. Choi, N. I. Han, and S. K. Yoon, "Inflammatory cytokines and change of Th1/Th2 balance as prognostic indicators for hepatocellular carcinoma in patients treated with transarterial chemoembolization", Sci Rep, 9(1), 1-8 (2019).
79. M. Márquez, C. Fernández-Gutiérrez, M. Montes-de-Oca, M. Blanco, F. Brun, C. Rodríguez-Ramos, and J. Girón-González, "Chronic antigenic stimuli as a possible explanation for the immunodepression caused by liver cirrhosis", Clin Exp Immunol, 158(2), 219-229 (2009).

80. N. Sipeki, P. Antal-Szalmas, P. L. Lakatos, and M. Papp, "Immune dysfunction in cirrhosis. World journal of gastroenterology", WJG, 20(10), 25642577 (2014).

81. H. Tilg, A. Kaser, and A. R. Moschen, "How to modulate inflammatory cytokines in liver diseases", Liv Int, 26(9), 10291039 (2006). 


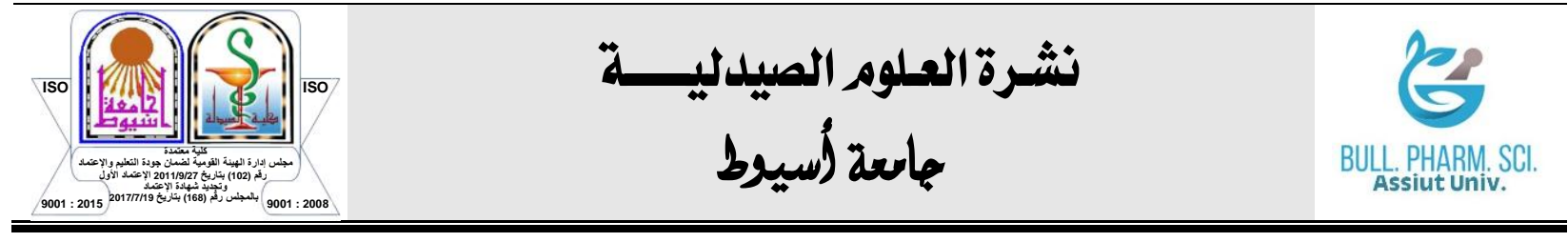

\section{مظاهر التباين في السيتوكينات لمرضى تشمع الكبا الفيروسي والغير فيروسي}

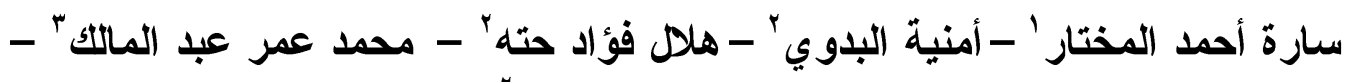
نها عبد الحليم عفيفي البون

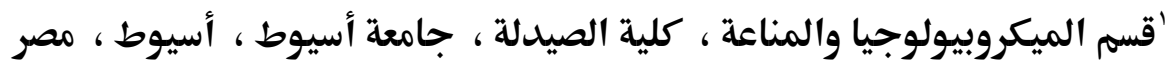

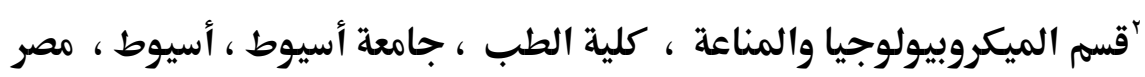

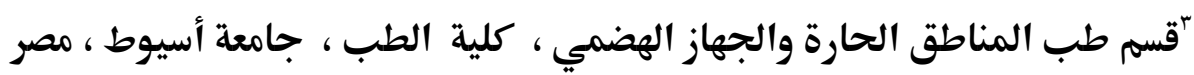

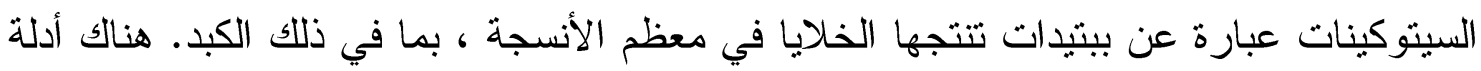

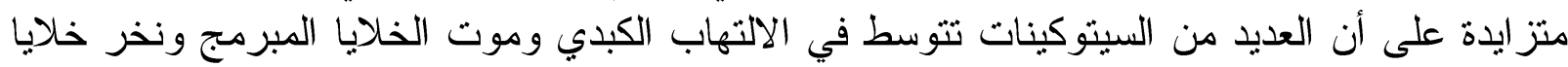

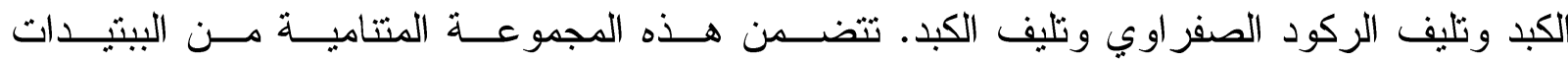

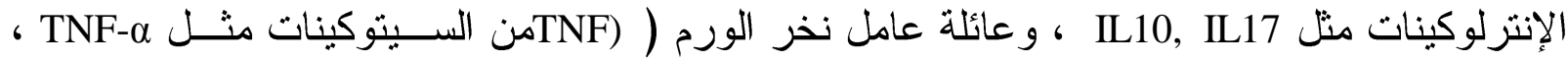

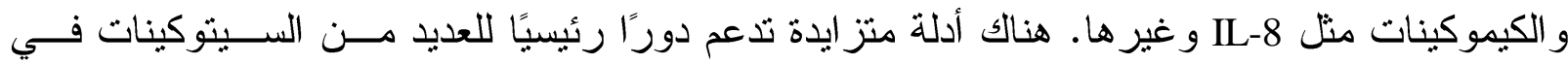

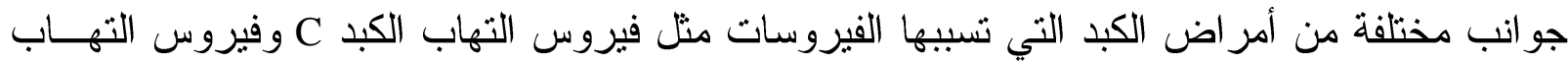

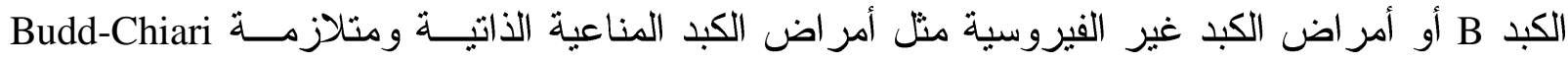

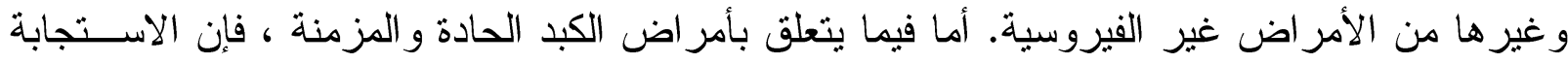

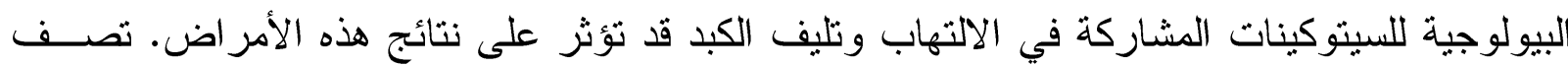

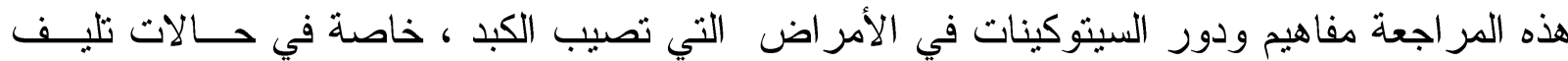

